\title{
Migration, moult and climate change in barn swallows Hirundo rustica in South Africa
}

\author{
Anders Pape Møller ${ }^{1, *}$, Rick Nuttall ${ }^{2}$, Steven E. Piper ${ }^{3, \mp}$, Tibor Szép ${ }^{4}$, \\ Edward J. Vickers ${ }^{5}$ \\ ${ }^{1}$ Laboratoire d'Ecologie, Systématique et Evolution, CNRS UMR 8079, Université Paris-Sud, Bâtiment 362, \\ 91405 Orsay Cedex, France \\ ${ }^{2}$ National Museum, PO Box 266, Bloemfontein 9300, South Africa \\ ${ }^{3}$ School of Biological and Conservation Sciences, University of KwaZulu-Natal, Private Bag X01, Scottsville 3209, \\ KwaZulu-Natal, South Africa \\ ${ }^{4}$ Institute of Environmental Science, College of Nyíregyháza, PO Box 166, 4401 Nyíregyháza, Hungary \\ ${ }^{5}$ Mount Moreland, Durban, South Africa
}

\begin{abstract}
Phenological change in long-distance migratory birds has responded less to climate change than that in short-distance migrants and residents. A general lack of information about the timing of migration in the winter quarters has prevented progress in interpreting the causes. Here we report long-term information on first arrival of barn swallows Hirundo rustica to-and last departure from - a major roost in South Africa during 1993-2010, a period when climate change at the breeding grounds was particularly pronounced. Although first arrival in autumn advanced by more than $2 \mathrm{wk}$, there was a tendency for a delay in last departure during spring, suggesting that cues for earlier spring departure from the winter quarters were missing. During 1999-2009, timing of moult was delayed, which may explain why spring migration by trans-Saharan migratory birds did not advance in this period.
\end{abstract}

KEY WORDS: Arrival date $\cdot$ Departure date $\cdot$ Long-distance migrant $\cdot$ Moult score

\section{INTRODUCTION}

Recent responses to climate change include earlier arrival and departure of migratory birds (e.g. Lehikoinen et al. 2004, Parmesan 2006, Schwartz et al. 2006). Migratory birds now arrive considerably earlier at their breeding grounds than just a few decades ago, although there is considerable variation among species (e.g. Lehikoinen et al. 2004, Rubolini et al. 2007, Lehikoinen \& Sparks 2010). Furthermore, they also depart earlier on autumn migration, but with significant variation among species (e.g. Jenni \& Kéry 2003, Lehikoinen \& Sparks 2010). Long-distance migratory birds have, on average, responded less in terms of phenology to climate change than short- distance migrants and residents (Sanderson et al. 2006, Møller et al. 2008). The mean start of spring singing in birds in Germany advanced the most in residents and the least in long-distance migrants, with an intermediate advance in short-distance migrants (Rubolini et al. 2010). The causes for this apparent lack of response in long-distance migrants include: (1) an inability of birds at the winter quarters to respond to climate change at the breeding grounds, because there are no cues there prompting an advance in breeding ground phenology (Both \& Visser 2001, Lehikoinen et al. 2004, Rubolini et al. 2007, Jones \& Cresswell 2010, Lehikoinen \& Sparks 2010); (2) variation in carry-over effects from when an individual was hatched to when it migrated, moulted and started to 
reproduce (Møller et al. 2009) (this process could progress over many years if there is a long-term trend in spring warming, and such an effect may be either genetic or maternal); and (3) photoperiod control of maturation of gonads, gonadal regression and timing of start of moult will not change if winter quarters of migrants remain unchanged because the photoperiod remains the same (even when a photoperiodic response is fine-tuned by factors such as temperature at the breeding grounds [Dawson 2005, 2008]). Migratory response to climate change could be constrained by genetic correlations between timing of egg laying and timing of autumn migration (Coppack et al. 2001) and between onset of autumn migration and timing of juvenile moult (Pulido \& Coppack 2004). Here we assess whether timing of annual moult in winter may prevent migratory birds from departing earlier for the breeding areas in spring.

Barn swallows are aerially insectivorous birds with a protracted moult of primaries lasting 4.5 mo (Ginn \& Melville 1983). Most barn swallows do not moult and migrate simultaneously because of elevated flight costs for a bird with missing feathers (Berthold 2001). Thus a barn swallow arriving in South Africa on 15 September will have finished its primate moult by early March, whereas a barn swallow arriving on 15 October will have finished its moult by early April. Migration from southern Africa to northern Europe lasts a minimum of $5 \mathrm{wk}$ (Glutz von Blotzheim \& Bauer 1994, p. 415), allowing an early moulting individual to arrive mid-April and a late moulting individual to arrive mid-May.

The objective of the present study was to estimate to what extent arrival at and departure from the winter quarters of a long-distance migrant have changed in recent years, as predicted from altered timing of arrival and departure from the breeding grounds. In addition, we tested whether the timing of moult, which constitutes a major activity of many migrants during winter (Ginn \& Melville 1983), has advanced, as predicted if earlier arrival from the breeding grounds would allow an earlier initiation of moult. If moult did not advance in recent years, any delay in spring departure from the winter quarters could be due to lack of change in timing of moult. We assessed these predictions using unique data on barn swallows Hirundo rustica collected in the South African winter quarters during 1993-2009, with migration data deriving from a roost near Durban in eastern South Africa and moult data from roosts near Bloemfontein in central South Africa. These 2 populations are likely to represent different breeding populations as reflected by recoveries of barn swallows of known breeding origin (Møller et al. 2006, Szép et al. 2006, 2009, Ambrosini et al. 2009).

\section{MATERIALS AND METHODS}

\subsection{Arrival and departure dates}

Edward Vickers (E.J.V.) recorded the first arrival in autumn and the last barn swallows in spring at a major roost in Mount Moreland, Durban, South Africa. This roost contains hundreds of individuals from the start in early autumn to the end in late spring, with numbers in midwinter peaking at 1 to 5 million barn swallows. Because E.J.V. lives next to the roost (distance $100 \mathrm{~m}$ ), he could reliably record first and last records of barn swallows. These records always consisted of many individuals, with the exact number also being recorded (3-10 in autumn and 3-100 in spring), thus preventing records from relying on an observation of a single individual. These numbers of birds seen were used as indices proportional to total population size, although they are likely to provide noisy estimates. Phenological data of first observations are in general not representative of the phenology of the population, unless annual population numbers are accounted for (Lehikoinen \& Sparks 2010).

\subsection{Changes in timing of moult}

To test whether there has been a temporal trend in timing of moult, we recorded moult scores of 3368 barn swallows captured with mist nets at roosts in Bloemfontein during 1999-2009. The mean $( \pm$ SE) number of individuals scored per year was $481 \pm 160$. Mean annual date of capture was 20 February $( \pm 8 d)$, with an overall mean of 1 March $( \pm 0.4 \mathrm{~d})$. All captured individuals were sexed and aged using standard procedures reported by Svensson (2006). Aging can be determined with certainty based on colour and tail length except for a few cases. Thus individuals were scored as juveniles, adults or unknown in a few cases. Sexing of barn swallows in the winter quarters is more difficult; juveniles cannot be sexed from external morphology whereas adults can be sexed based on tail length if tail feathers are not broken, as is often the case in winter. Thus, adults were scored as males, females, possible males, possible females or unknown.

Wing and tail moult was given a standard score for each feather with a score of 0 for an unmoulted feather and a score of 5 for a newly moulted feather, with intermediate integers given to intermediate stages of moult, reflecting the progression of moult (Ginn \& Melville 1983). We used total moult score for wing and tail feathers as a measure of moult status of an individual. Because moult in the barn swallow advances linearly with capture date in the season (Ginn \& Melville 1983), we analysed moult score after adjusting for capture 
date, with later moult being inferred from a lower moult score for a given date.

We developed a full mixed model of $\log _{10}$-transformed moult score as the response variable and sex, age, date, year (a fixed continuous variable), a random effect of year and date $\times$ year as predictors.

\subsection{Statistical analyses}

We used JMP for the statistical analyses (SAS Institute 2000). All individuals were only included once, although the very small number of recaptures would make no difference to the results. We tested for a trend in arrival and departure dates by including year as a continuous predictor variable. There was no significant residual temporal autocorrelation in arrival and departure dates at time lags of $\geq 1 \mathrm{yr}$. The observed autocorrelation coefficients, using the Time Series Analysis platform in JMP, were 0.15 and -0.17 for time lags of $1 \mathrm{yr}$ and were far from statistically significant.

\section{RESULTS}

\subsection{Arrival and departure dates}

First arrival at the winter quarters advanced highly significantly during the course of the study, with a predicted advance of $24 \mathrm{~d}$, or a mean $( \pm \mathrm{SE})$ of $1.35 \pm 0.21 \mathrm{~d}$ per year (Fig. 1a). In contrast, there was a delay in last departure date during spring (Fig. 1b). We included the number of individuals seen on the first day in autumn (or the last day in spring) in the model, but this variable did not predict temporal change in phenology (autumn: $F_{1,14}=1.11, \mathrm{p}=0.31$; spring: $F_{1,10}=2.00$, $\mathrm{p}=0.19$ ), and the temporal trends remained significant after adjustment for number of individuals seen (autumn: $F_{1,14}=40.16, \mathrm{r}^{2}=0.74, \mathrm{p}<0.0001$, slope $[\mathrm{SE}]=$ -1.337 [0.211], spring: $F_{1,10}=8.78, \mathrm{r}^{2}=0.47, \mathrm{p}=0.014$, slope $[\mathrm{SE}]=0.894[0.302])$.

\subsection{Moult scores}

Moult score was significantly explained by 5 factors, accounting for $74 \%$ of the variance (Table 1). Moult score showed a significant year $\times$ date interaction, with the negative slope implying that, for a given date, moult score significantly decreased by year (Table 1). Thus moult was delayed in recent years (Fig. 1c). Moult score was significantly delayed in juveniles compared with adults, and males had larger moult scores than females (Table 1).
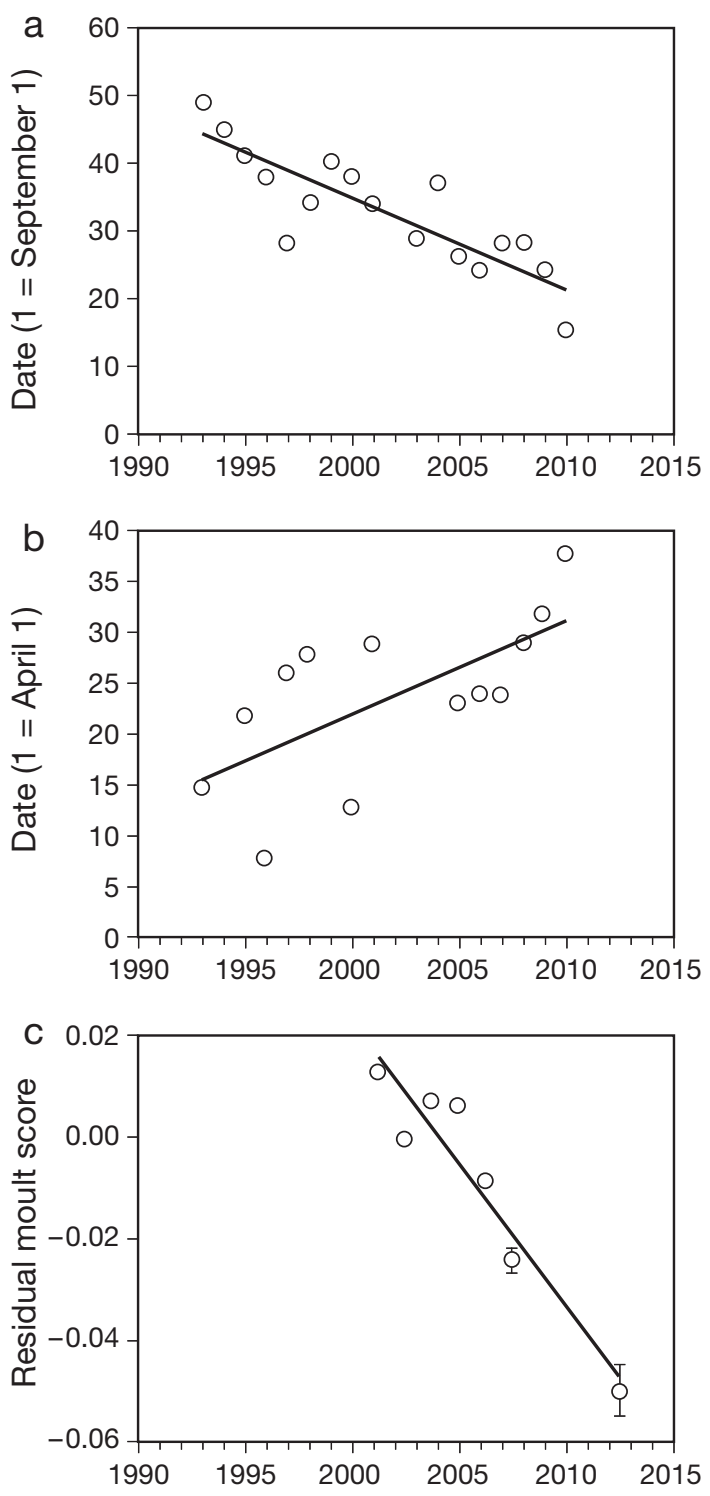

Fig. 1. Hirundo rustica. (a) Autumn arrival date (1 = 1 September), (b) spring departure date ( $1=1$ April) and (c) annual mean $( \pm \mathrm{SE})$ moult score estimates of barn swallows. Residual moult scores are residuals from a model that included the effects of date, sex and age as reported in Table 1. Statistics describing the model are: (a) $F_{1,15}=40.80, \mathrm{r}^{2}=0.73, \mathrm{p}<0.0001$, slope $(\mathrm{SE})=-1.350(0.211)$; (b) $F_{1,11}=8.50, \mathrm{r}^{2}=0.44, \mathrm{p}=0.014$, slope $(\mathrm{SE})=0.917(0.315)$. Solid lines: linear regression

\section{DISCUSSION}

First observations of migratory birds are known to be less reliable than mean or median dates (Lehikoinen \& Sparks 2010), although first and median dates are positively correlated for a Danish barn swallow population (Møller 2008) and a Spanish barn swallow population (F. de Lope pers. comm.). Western Palearctic barn swallows winter in sub-Saharan Africa, with populations 
Table 1. Hirundo rustica. Moult scores ( $\log _{10}$-transformed) of barn swallows at Bloemfontein in relation to year, date, year $\times$ date interaction, age and sex. The model had the statistics $F_{15,3351}=636.36, \mathrm{r}^{2}=0.74, \mathrm{p}<0.0001$

\begin{tabular}{|lccccc|}
\hline Factor & Sum of squares & df & $F$ & $p$ & Slope (SE) \\
\hline Year & 0.050 & 1 & 30.19 & & $-0.0133(0.0024)$ \\
Date & 5.698 & 1 & 3423.70 & & $0.00244(0.00004)$ \\
Year $\times$ Date & 0.042 & 1 & 24.95 & $<0.0001$ & $0.00013(0.00003)$ \\
Age & 1.8625 & 2 & 559.50 & $<0.0001$ & \\
Sex & 0.055 & 4 & 8.31 & $<0.0001$ & \\
Intercept (Year) & & 6 & 9.26 & $<0.0001$ & \\
Error & 5.577 & 3351 & & & \\
\hline
\end{tabular}

from different breeding areas being segregated (Møller et al. 2006, Szép et al. 2006, 2009, Ambrosini et al. 2009). Birds wintering around Durban, where we recorded first arrival and last departure dates, breed in parts of eastern Europe that include Belarus and Ukraine, whereas birds wintering around Bloemfontein, which we studied with respect to moult, have a more northern breeding distribution (Møller et al. 2006).

Three different hypotheses may account for advances in arrival and delays in departure of barn swallows. The first hypothesis is that the inability to respond to climate change is due to an absence of altered cues in the winter quarters (Lehikoinen et al. 2004, Rubolini et al. 2007, Lehikoinen \& Sparks 2010). This could apply to the present study because changes in timing of migration are not affected by changes in climate in southern Africa (Møller 2008), and departure of long-distance migrants from South Africa seems to be determined by day length (Kok et al. 1991). However, we note that Saino et al. (2007) have shown that rainfall and temperature anomalies in Africa weakly predict the timing of spring migration of trans-Saharan migrants including the barn swallow. The related phenology mismatch hypothesis could apply if spring arrival has advanced, leading to earlier breeding and an increase in frequency of second clutches, with some birds departing earlier from the breeding grounds and arriving earlier at the winter quarters. Those with 2 clutches may depart later, arriving later to the winter quarters, leading to later moult and later departure for spring migration, as observed in the present study. However, several pieces of evidence are inconsistent with this mismatch hypothesis. (1) Barn swallows from Durban and Bloemfontein are likely to breed in Ukraine, Belarus and other parts of eastern Europe (Møller et al. 2006) where breeding date has not advanced during 1991-2010 (A.P.M. unpubl. data). (2) Earlier arrival at the breeding grounds is associated with a reduction in variance in arrival date (Møller 1994b, 2008), and thus not an increase as expected for the mismatch hypothesis. (3) The frequency of second clutches has not increased in Denmark, Italy or Spain (Møller et al. 2010, N. Saino and F. de Lope pers. comm.). (4) The end of the breeding season has not changed during 1971-2010 in Denmark (Møller et al. 2010). (5) The delay in timing of moult, as reported here, applies to both yearlings and older birds, despite the fact that older birds are known more often to have 2 clutches and hence terminate breeding late (Møller 1994a). The second hypothesis is that there is variation in carryover effects from when an individual was hatched to when it migrated, moulted and started to reproduce (Møller et al. 2009). Birds that breed earlier may migrate earlier in autumn leading to earlier arrival in Africa. However, the delay in moult and spring departure observed here is inconsistent with this hypothesis. The third hypothesis is that photoperiod control of maturation of gonads, gonadal regression and timing of start of moult may be fine-tuned by factors such as temperature (Dawson 2005, 2008). This hypothesis may account for the fact that moult is delayed despite an earlier arrival at the wintering grounds.

Timing of spring migration may be affected by the fact that many long-distance migrants moult during winter (Ginn \& Melville 1983). There is no published information on changes in timing of moult in recent decades as a consequence of phenological changes in the annual cycle. However, experimental increases in temperature can advance timing of testicular regression after breeding, but they also advance timing of post-nuptial moult (Dawson 2005). We have shown here, using extensive moult data since 1999, that moult stage has become delayed for a given date. This implies that although the first barn swallows arrive earlier at their South African winter quarters in autumn, they do not advance the timing of their moult (which is determined by temperature) and hence do not start their spring departure earlier, because the long duration of moult does not leave any time before spring migration starts (see Section 1). These findings suggest that response in migration phenology during winter may be prevented by a lack of response of moult timing.

In conclusion, we have shown divergent changes in spring and autumn migration of a long-distance migratory bird in its South Africa winter quarters as reflected by last spring and first autumn observations. In addition, the annual winter moult in Bloemfontein was significantly delayed, consistent with the delay in last spring departure dates from the Durban roost. These findings suggest that factors in the winter quarters rather than in the breeding areas may account for the lack of phenological response of long-distance migratory birds to climate change. 
Acknowledgements. We thank G. Grobler, F. Conradie, D. de Swardt, J. van Niekerk, J. Kok, G. Skinner, A. Botha, S. Byrkjeland, I. Grastveit, H. Bjordal, A. Pierce and B. van den Brink for field assistance. T.S. thanks the OTKA 69068 grant for funding.

\section{LITERATURE CITED}

Ambrosini R, Møller AP, Saino N (2009) A quantitative measure of migratory connectivity. J Theor Biol 257:203-211

Berthold P (2001) Bird migration. Oxford University Press, Oxford

Both C, Visser ME (2001) Adjustment to climate change is constrained by arrival date in a long-distance migrant bird. Nature 411:296-298

Coppack T, Pulido F, Berthold P (2001) Photoperiodic response to early hatching in a migratory bird species. Oecologia 128:181-186

Dawson A (2005) The effect of temperature on photoperiodically regulated gonadal maturation, regression and moult in starlings: potential consequences of climate change. Funct Ecol 19:995-1000

> Dawson A (2008) Control of the annual cycle in birds: endocrine constraints and plasticity in response to ecological variability. Philos Trans R Soc Lond B 363:1621-1633

Ginn HB, Melville DS (1983) Moult in birds. British Trust for Ornithology, Tring

Glutz von Blotzheim UN, Bauer KM (1994) Handbuch der Vögel Mitteleuropas. Vol. 9. AULA-Verlag, Wiesbaden

> Jenni L, Kéry M (2003) Timing of autumn bird migration under climate change: advances in long-distance migrants, delays in short-distance migrants. Proc R Soc Lond B 270: $1467-1471$

Jones T, Cresswell W (2010) The phenology mismatch hypothesis: Are declines of migrant birds linked to uneven global change? J Anim Ecol 79:98-108

Kok OB, Van Ee CA, Nel DG (1991) Daylength determines departure date of the spotted flycatcher Muscicapa striata from its winter quarters. Ardea 79:63-66

Lehikoinen E, Sparks TH (2010) Changes in migration. In: AP Møller, W Fiedler, P Berthold (eds) Effects of climate change birds. Oxford University Press, Oxford, p. 89-112

Lehikoinen E, Sparks TH, Zalakevicius M (2004) Arrival and departure dates. In: AP Møller, W Fiedler, P Berthold (eds) Birds and climate change. Elsevier, Amsterdam, p. 1-31

Møller AP (1994a) Sexual selection and the barn swallow. Oxford University Press, Oxford

Møller AP (1994b) Phenotype-dependent arrival time and its consequences in a migratory bird. Behav Ecol Sociobiol 35:115-122

Møller AP (2008) Distribution of arrival dates in a migratory

Editorial responsibility: Nils Chr. Stenseth,

Oslo, Norway bird in relation to environmental conditions, natural selection and sexual selection. Ethol Ecol Evol 20:193-210

Møller AP, Hobson KA, Mousseau TA, Peklo AM (2006) Chernobyl as a population sink for barn swallows: tracking dispersal using stable isotope profiles. Ecol Appl 16: 1696-1705

Møller AP, Rubolini D, Lehikoinen E (2008) Populations of migratory bird species that did not show a phenological response to climate change are declining. Proc Natl Acad Sci USA 105:16195-16200

Møller AP, Flensted-Jensen E, Mardal W (2009) Adjustment of the annual cycle to climatic change in a long-lived migratory bird species. Curr Zool 55:92-101

Møller AP, Flensted-Jensen E, Klarborg K, Mardal W, Nielsen JT (2010) Climate change affects the duration of the reproductive season in birds. J Anim Ecol 79:777-784

Parmesan C (2006) Ecological and evolutionary responses to recent climate change. Annu Rev Ecol Evol Syst 37:637-669

Pulido F, Coppack T (2004) Correlation between timing of juvenile moult and onset of migration in the blackcap, Sylvia atricapilla. Anim Behav 68:167-173

> Rubolini D, Møller AP, Rainio K, Lehikoinen E (2007) Intraspecific consistency and geographic variability in temporal trends of spring migration phenology among European bird species. Clim Res 35:135-146

Rubolini D, Saino N, Møller AP (2010) Migratory behaviour constrains the phenological response of birds to climate change. Clim Res 42:45-55

> Saino N, Rubolini D, Jonzén N, Ergon T, Montemaggioru A, Stenseth NC, Spina F (2007) Temperature and rainfall anomalies in Africa predict timing of spring migration in trans-Saharan migratory birds. Clim Res 35:123-134

Sanderson FJ, Donald PF, Pain DJ, Burfield IJ, van Bommel FPJ (2006) Long-term population declines in Afro-Palearctic migrant birds. Biol Conserv 131:93-105

SAS Institute (2000) JMP. SAS Institute, Cary, NC

> Schwartz MD, Ahas R, Aasa A (2006) Onset of spring starting earlier across the Northern Hemisphere. Glob Change Biol 12:343-351

Svensson L (2006) Identification guide to European passerines. British Trust for Ornithology, Thetford

Szép T, Møller AP, Piper S, Nuttall R, Szabó DZ, Pap PL (2006) Searching for potential wintering and migration areas of a Danish barn swallow population in South Africa by using an NDVI and a survival method. J Ornithol 147: $245-253$

> Szép T, Hobson KA, Vallner J, Kovacs B, Szabo DZ, Møller AP (2009) Comparison of trace element and stable isotope approaches to the study of migratory connectivity: an example using two hirundine species breeding in Europe and wintering in Africa. J Ornithol 150:621-636

Submitted: November 24, 2010; Accepted: April 3, 2011

Proofs received from author(s): June 22, 2011 